\title{
TEAMWORK AND LEADERSHIP TRAINING FOR HEALTH WORKERS - IS IT WORTH IT?
}

\section{Peter Nightingale, GP; Adrian Ibbetson, Lecturer; Rob Pugh, Trainer}

\section{SUMMARY}

A group of general practice (GP) registrars, GP trainers and student district nurses from North Lancashire and Cumbria attended a one-day event to focus on learning skills related to teambuilding and leadership relevant to work in primary care. A detailed evaluation of the impact of this experience was undertaken.

'Team maintenance' type behaviours (aspects of selfawareness and awareness of others, communication, listening and encouragement and support) were significantly improved by the educational event. Delegates reported that the event would be helpful for their work within the National Health Service (NHS) as an organisation. They clearly enjoyed the day.

\section{INTRODUCTION}

Over recent years a multidisciplinary 'away day' has been incorporated into the day release course for vocational training for general practice in Morecambe Bay. This has been possible due to the support of the department of Postgraduate Medicine and Dentistry in Manchester. We have worked together with the district nursing students based at St Martin's College, Lancaster.

The reasons for including this day were as follows:

- Teamwork was identified as one of the four generic competencies required of professionals working in health by Sheffield University (the others being management (especially time), problem-solving and communication) (Levy, 1992).

- Interdisciplinary working and learning has received the endorsement of the General Medical Council (1993) and various other substantial reports but little integration of education had occurred in practice.

- There has been a recent emphasis on doctors and nurses working together more effectively ${ }^{(1)}$. A key element of this process was considered to be joint training whenever possible

- Good Medical Practice for General Practitioners ${ }^{(2)}$ clearly states that healthcare is increasingly delivered by multidisciplinary teams and that we must communicate effectively with colleagues both within and outside the team.

\section{EXPLANATION OF PROGRAMME CONTENT AND DELIVERY METHODS:}

The Primary Care Leadership and Training Development
Programme took place at a training venue near Kendal in Cumbria on 26th June 2002. It had been preceded a week before by a theoretical classroom session consisting of basic team working theory (See Appendix 1) and the application of the Belbin Self-Perception Inventory.

The stated programme objectives were:-

1. To increase general awareness of team team-working issues and to implement learning in practical exercises.

2. To develop the working relationship between representative client groups.

3. To explore issues of leadership.

4. To assist in the break down of negative-impacting professional barriers.

5. Focus on learning through fun and enjoyment of the day's programme.

The approach to the programme was an experiential one using 'hands on' exercises (see appendix 2). This allowed individuals to apply learning in a practical way in an environment conducive to experimentation and selfdiscovery.

The experiential learning experience was optimised by utilising the processing cycle $^{(3)}$.

This consists of five stages:-

- experiencing - the learner experiences the event as it unfolds

- Publishing - learners are asked for specific details of observations with no analysis

- Analysing - learners disclose their reactions to what has occurred

- generalising - how can this experience be related to the real world

- applying - learners reflect on how they will apply anything learned in their current or future situation.

Many of the activities were created to mirror real life working issues such as working in inter-dependent subgroups who need to achieve a high degree of collaboration in order to achieve a shared objective.

The programme was delivered through a series of short group-oriented seminars and practical exercises, most of which happened outdoors. There was a strong focus on inclusiveness and opportunity for challenge using a 'Challenge by Choice' framework. The day started with a workshop where sub-teams identified the key characteristics of world-class teams. This checklist then became a review model for the process analysis that all teams undertook after 
any activity. This review identified particular strengths and development needs of both teams and individuals. Tutors then helped participants to reinforce the most important aspect of the programme, namely identifying how to transfer and apply this learning effectively back in the work place.

The morning then consisted of two contrasting exercises. The first challenged the teams to make a journey keeping the whole team off the ground with limited resources. The second asked two teams to collaborate in the design and building of a structure to keep a ball rolling continuously for a set time period. Although great fun was had by all, the delegates were reminded that the activities were just the catalyst for analysing the team processes and the reviews always focussed on 'how' things were done, 'what' can be learned from this, and 'how' this learning can be applied in a real working environment; not on 'what' was done. After all, it's not particularly useful for doctors and nurses to know how to transport themselves over a 'toxic swamp'.

The afternoon consisted of an extended self-managed project that required the completion of 25 separate tasks within a set time period in order to gain a code that, once cracked, led to a reward. The participants worked as one large team, constantly reviewing their team processes and progress. The objectives were met, the reward gained and the champagne flowed.

Finally, the participants split into their sub-groups once again to undertake an end of programme review and generate personal action plans stating how they were going to implement the learning from the day once back in the work place. These were shared with the group and the post-course evaluation questionnaires were administered .

\section{NEED FOR EVALUATION}

The decision to build an evaluation into the learning event had several contributing factors. From a quality assurance perspective, there was a need to investigate whether or not the aims and objectives were being met. In this respect, the evaluation would provide feedback to the programme tutor and the course provider that could inform future design decisions about the learning event. Furthermore the evaluation could be used to provide feedback to the organisational sponsor of the programme with regard to outcomes, in order that expenditure might be justified.

From an external perspective, although having many advocates, the value of the use of metaphoric problemsolving activities that involve an outdoor context is largely unsubstantiated $^{(4,5,6)}$. Therefore an evaluation of the outdoor learning event would serve a number of purposes.

\section{METHOD}

The evaluation of the event took the form of a simple pre-test test/post-test methodology that was limited to investigating reactions to the learning event and perceptions of learning from $\mathrm{it}^{(7)}$ The pre-test investigated participants' expectations of the event and the post-test attempted to determine perceived outcomes from the event. The event distinguished between two different types of behaviours: task and maintenance. Task behaviours related to aspects of leadership, decision-making, planning, problem- solving and time management. Maintenance behaviours related to aspects of self-awareness and awareness of others, communication, listening and encouragement and support. Therefore potential outcomes were investigated in the context of relating to these two dimensions. The delegates were also probed on issues relating to their enjoyment of the event and their perceptions of benefit, both to them as individuals and to the organisation (i.e. the NHS). The questionnaire employed was a modification of that used in previous research ${ }^{(7.8)}$.

Through logistical reasons and choice, not everyone at the event completed both the pre-test and post-test questionnaires. A, as a result the data presented comprises a sample of 33 delegates. The data (scores) presented were generated by delegates responding to items on a 7 point Likert scale ( $1=$ 'strongly disagree', $2=$ 'disagree', $3=$ 'somewhat disagree', 4 = 'unsure', 5 = 'somewhat agree', $6=$ 'agree' and $7=$ 'strongly agree'). Six items related to the 'task' sub-scale; six related to the maintenance sub-scale; two related to the enjoyment sub-scale; and, a further two related to the benefit sub-scale.

\section{RESULTS}

Figure 1 demonstrates that delegates reported somewhat 'neutral' expectations ( 4 = 'unsure') when asked how far the event might improve task-related behaviours behaviours, and not much improvement in those behaviours was reported (mean pre $=4.65$, mean post $=4.79$ ). Delegates had relatively more positive expectations regarding the development of maintenance-related behaviours and they reported 'somewhat' positive outcomes in terms of the development of such behaviours (mean pre $=4.85$, mean post $=5.20$ ) (Figure $1)$. The difference pre- to post- was significantly different $(\mathrm{t}=3.60, \mathrm{p}<0.01)$. These findings are interesting because the learning event was 'framed' in advance and then reviewed on the day itself in considerationwith regard to of the importance of 'maintenance-type' behaviours, emphasising the danger of being too task-focused. Links were made from the activities to the workplace regarding this issue.

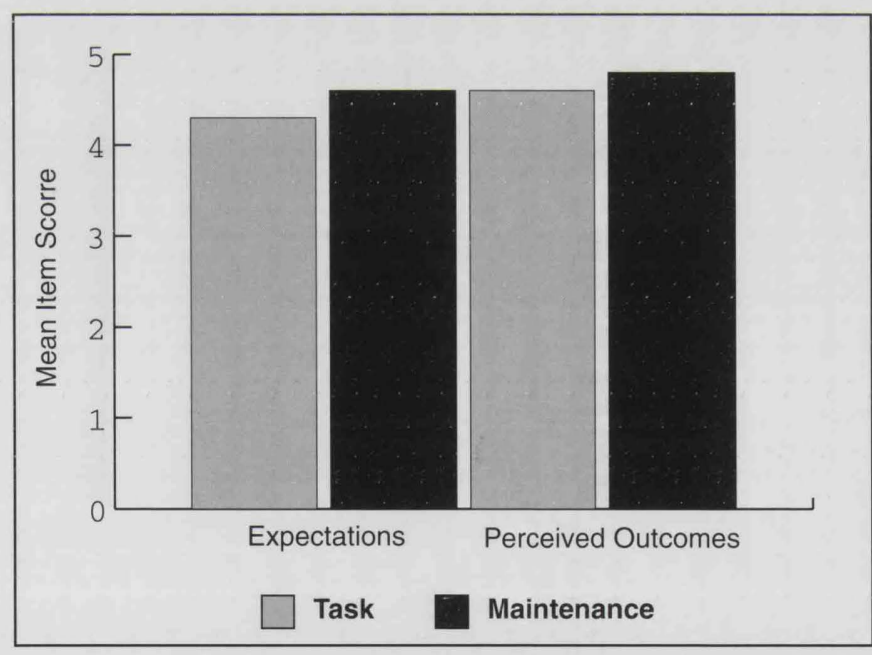

Figure 1 Reported expectations and perceived outcomes relating to task \& maintenance behaviours

From Figure 2 it is evident that expectations regarding the enjoyment of the event were tempered by 'pre-match nerves' but that the delegates clearly reported that they enjoyed the event. This difference was statistically significant $(t=5.70$, $\mathrm{p}<0.01)$. Reassuring delegates that they need not be apprehensive about their ability to cope with this particular ('low level' - in terms of physicality) activity programme ('low level' - in terms of physicality) might be a consideration for future briefing sessions. 


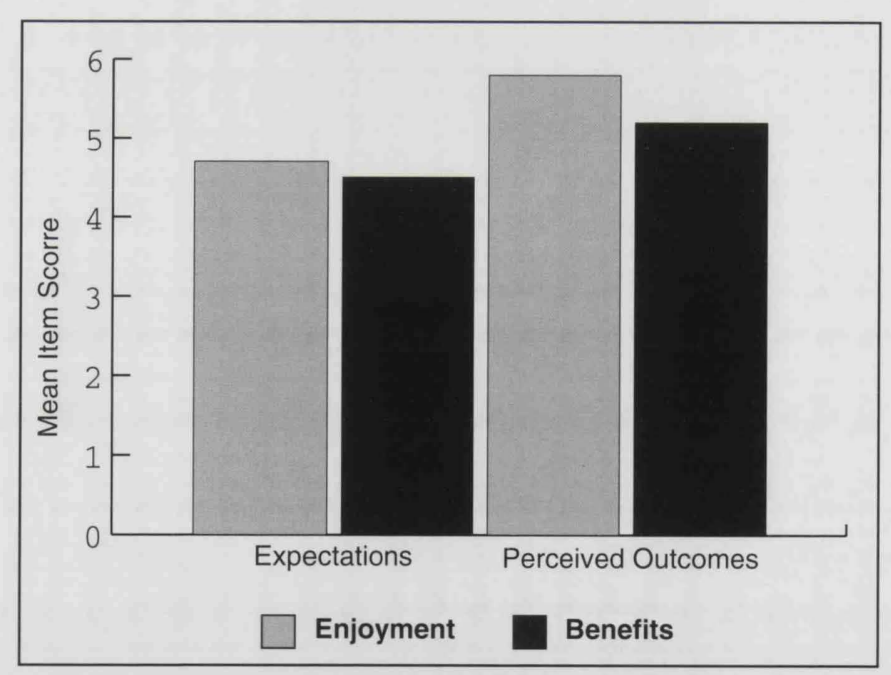

Figure 2 Expectations and perceived outcomes relating to reported enjoyment \& perceived benefits

The delegates were asked about how much they thought that the event would benefit them individually and how they thought that it would benefit the organisation (i.e. the NHS). As can be seen above, in terms of expectations, delegates were 'somewhat' in agreement that the event would be beneficial (mean score 4.98). Their level of reported benefits after the event was higher than their initial expectations (mean score 5.41). This difference was statistically significant $(\mathrm{t}=3.97, \mathrm{p}<0.01)$. Interestingly delegates reported perceived individual benefits that were consistent with their expectations (pre mean item score $=5.48$, post mean item score $=5.55$ ). The major shift was in the amount of benefit to the organisation (pre mean item score $=4.36$, post mean item score $=5.27$ ). Therefore future 'framing' of the event might wish to concentrate on 'selling' the benefits to the NHS as an organisation in order to get the most out of the activity day.

\section{CONCLUSION}

This study adds support to the value of health workers learning about teamwork and leadership in a multidisciplinary setting. Feedback from groups in past years has clearly shown the events to be enjoyable, as was this year's event.

However, with not having previously used this more rigorous form of evaluation, we have never before demonstrated the shift in awareness of team maintenance skills that were reported in this study. These skills were considered useful for work within the NHS.

\section{FURTHER CONTACTS}

Peter Nightingale, GP Trainer, pbnightingale@bigfoot.com

Adrian Ibbetson, Lecturer, Tourism \& Leisure Management, abibbetson@uclan.ac.uk

Rob Pugh, trainer, Rob.Pugh1@Btopenworld.com

\section{APPENDIX 1}

\section{NOTES ON BASIC THEORY ON TEAMWORK AND LEADERSHIP}

A team is an energetic group of people who are committed to achieving common objectives, who work well together and enjoy doing so and who produce high quality results ${ }^{(9)}$.

The following have a good influence on team work:-

- clear objectives with agreed goals

- openness and confrontation

- support and trust

- co-operation and conflict resolution

- sound procedures

- leadership

- regular review

- individual development

- sound intergroup relations

The Belbin Self-perception Inventory is a useful tool for exploring an individual's team role or style when functioning in a team.

Guidelines for teamwork and leadership:-

- be accessible - do not avoid your team

- keep colleagues informed by giving clear and comprehensible instructions

- provide opportunities to participate in decisions affecting them

- allow airing of grievances - do not suppress criticism

- give feedback about work achieved

- encourage innovation and feedback

- leadership and teamwork go hand- in- hand. Teams may rotate the leadership role.

Leaderless teams frequently malfunction.

There are at least two different kinds of leadership:-

- leadership of tasks

- leadership of people

Most people find it easier to do one or the other but some can do both.

Task leadership requires:-

- concentration

- focus

- clear head

People leadership requires:-

- involvement

- enthusiasm

- warmth

Leadership is required when change is required. Some models of leadership from recent literature may help understanding.

Bennis and Nanus describe four behaviours that were important for success in their study of 90 outstanding leaders ${ }^{(10)}$.

1. vision

2. aligned community

3. trust in the team

4. relentless learning 
1. Vision Creating a compelling vision of the future state that is better than the status quo, and demonstrating some of the steps that will bring this about. Values are also important. They are the guiding principles of a group. Features of an inspiring vision are that it is:-

- imaginable

- desirable

- feasible

- focused

- flexible

- communicable.

The vision is built by a five stage process known as forcefield analysis. This process addresses:-

- what do we want to achieve together

- where are we now relative to this

- what is pushing us in the required direction

- what is holding us back

- how do we make progress - action planning

2. Creating an aligned community. Commitment is achieved by developing policies, systems and practices that are consistent with the vision described. The way people are trained and appraised, rewarded and disciplined must be consistent with the vision and values of the team

3. Trust. There are four elements to trust

- competence - team members need the ability and training to fulfil their role

- care - it is easier to trust someone who cares about your well-being

- consistency - inconsistency loses trust

- courage - there will be times when it is difficult to do what is right. Leaders may have to withstand criticism, controversy, resistance and even rebellion.

4. Learning both for leaders themselves and their group. Leaders tolerate uncertainty and error. They do not blame but learn. This gives people courage and confidence to take risks and make mistakes, without fear of recrimination.

\section{The climate for leadership}

Vision and values on which it is based form the basis of the culture of a team or organisation (the way people behave) as well as the climate (how people feel). Good leaders build and communicate a vision and also live by the values inherent in the vision. They thus create a climate which brings out the best in people.

Six factors have been identified that contribute to this climate. A favourable climate is linked to greater job involvement and commitment of time and energy. This in turn leads to superior performance.

1. Supportive management and leadership - no fear of reprisal with failure

2. Clarity of role - People know what is expected of them

3. Self-expression - True feelings and creativity can be expressed

4. Contribution - people feel they are making a contribution towards achieving goals

5. Recognition - people feel contributions are recognised

6. Challenge - people feel work is challenging and conducive to their development.

\section{APPENDIX 2}

PRIMARY CARE LEADERSHIP AND TRAINING DEVELOPMENT PROGRAMME 26th JUNE 2002 HOLMESCALES FARM, NEAR KENDAL

\section{Programme objectives :}

1. To increase general awareness of team- working issues and implement learning in practical exercises.

2. To develop the working relationship between representative client groups.

3. To explore issues of leadership.

4. To assist in the break down of negative- impacting professional barriers.

5. Focus on learning through fun and enjoyment of the day's programme.

Theoretical Input: The Belbin Self-Perception Inventory team roles will be used to help mediate the learning and focus on inter-personal relationships throughout the day.

\section{Outline Programme}

\begin{tabular}{|c|c|}
\hline Time & Activity \\
\hline $9.00 \mathrm{am}$ & Meet at Holmscales. Tea/coffee \\
\hline 9.20am & $\begin{array}{l}\text { Introduction from Pete Nightingale and Rob Pugh } \\
\text { - Aims for the Programme }\end{array}$ \\
\hline $9.30 \mathrm{am}$ & $\begin{array}{l}\text { Icebreaker exercise 'Balls Up': physical and } \\
\text { mental warm up }\end{array}$ \\
\hline $9.50 \mathrm{am}$ & $\begin{array}{l}\text { Short workshop: 'Characteristics of effective } \\
\text { teams. } \\
\text { Basic theory supporting team learning. Medical } \\
\text { checks }\end{array}$ \\
\hline 10.20am & $\begin{array}{l}\text { Outdoor Session One: Team A and B do } \\
\text { 'rollerball', Team C and D do 'juggernaut' plus } \\
\text { review }\end{array}$ \\
\hline 11.05am & Morning Coffee \\
\hline $11.25 \mathrm{am}$ & $\begin{array}{l}\text { Outdoor Session Two: Reverse of session One, } \\
\text { plus review }\end{array}$ \\
\hline 12.10am & Indoor morning review led by Rob \\
\hline 12.30pm & Lunch \\
\hline 1.15pm & $\begin{array}{l}\text { Project 'PC' - An extensive self- managed project } \\
\text { for all delegates lasting all afternoon. The whole } \\
\text { group is presented with a series of tasks that need } \\
\text { to be achieved in order to gain the code that } \\
\text { unlocks the 'booty chest'! Each task has to be } \\
\text { undertaken by a minimum number of participants, } \\
\text { some taking only a few whilst others may require } \\
\text { the whole group! }\end{array}$ \\
\hline $3.15 \mathrm{pm}$ & Compulsory interim review \\
\hline $3.35 p m$ & Project 'PC' continuation \\
\hline 4.20pm & Project 'PC' ends and finale \\
\hline 4.30pm & $\begin{array}{l}\text { Debrief and programme review with action } \\
\text { planning }\end{array}$ \\
\hline $5.15 p m$ & Depart \\
\hline
\end{tabular}




\section{REFERENCES}

1 Salvage J, Smith R. Doctors and nurses: doing it differently. Br Med J 2000;320:1019-20

2 RCGP/General Practitioners committee (BMA). Good Medical Practice for General Practitioners 2002

3 Midmar, D. The Processing Cycle. Br Med J Career Focus 2002;2 November:s140

4 Jones PJ, Oswick C. Outcomes of outdoor management development: articles of faith? J Eur Industr Training $1993 ; 17: 10-18$

5 Mazany P, Francis S, Sumich P. Evaluating the effectiveness of an outdoor workshop for team building in an MBA programme. Team Performance Management 1997; $3: 97-115$

6 McEvoy G, Buller P. The power of outdoor management development. Management Development 1997;16:208-217
7 Ibbetson AB, Newell S. Winner takes all: an evaluation of adventure-based experiential training. $\mathrm{J}$ Management Learning 1998;27:163-185

8 Ibbetson AB, Newell S. A comparison of a competitive and non-competitive outdoor management development programme: the role of evaluation. Personnel Review $1999 ; 28: 58-76$

9 Francis D, Young D. Improving work groups: a practical manual for teambuilding. University Associates Inc, Mansfield. 1979

10 Bennis W, Nanus B. Leaders: Strategies for taking charge. Harper and Rowe 1985

Acknowledgements: The authors would like to thank Sally Wilson and her colleagues and student district nurses from St Martin's College, Lancaster for their support in participating in this project. 